\title{
Massive Platelet Clumping on Peripheral Blood Smear and Pseudothrombocytopenia in a Patient with COVID-19
}

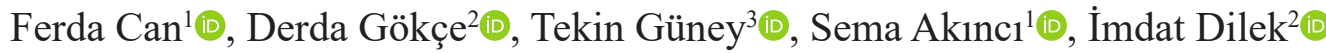 \\ ${ }^{1}$ Clinic of Hematology, Ministry of Health, Ankara City Hospital, Ankara, Turkey \\ ${ }^{2}$ Department of Hematology, Yıldırım Beyazıt University, Ankara City Hospital, Ankara, Turkey \\ ${ }^{3}$ Clinic of Hematology, University of Health Sciences, Ankara City Hospital, Ankara, Turkey
}

Pseudothrombocytopenia is often associated with ethylenediaminetetraacetic acid (EDTA) used in blood count tubes. It is essential to examine the peripheral smear of patients with thrombocytopenia and differentiate actual thrombocytopenia from pseudothrombocytopenia. ${ }^{1,2}$ COVID-19 is a new infectious agent for which immunological returns have not been clearly defined, and pseudothrombocytopenia has been reported as in COVID patients and has been associated with the binding of platelets due to typical EDTA. ${ }^{3,4}$ We think that it should be kept in mind that pseudothrombocytopenia in COVID-19 patients can be an effect of the changes in the endothelium as a result of the infection. Written informed consent was obtained from the patient.

A 67-year-old man was admitted to emergency service with cough, shortness of breath, lethargia, and fatigue. He had no medications. He was diagnosed with cyanotic and auscultation of the thorax showing coarse rales. Computer tomography image of the thorax showed bilateral multilobar peripherally located ground glass opacities which were charecteristic of COVID-19, and the polymerase chain reaction test for COVID-19 was positive. Laboratory test results showed a normal platelet count of $179 \times 10^{9} / \mathrm{L}$. Favipiravir was started immediately with enoxaparin sodium as the D-dimer level was $960 \mathrm{ng} / \mathrm{dL}$. On the third day of the admission, platelet count suddenly dropped to $22 \times 10^{9} / \mathrm{L}$. On peripheral smear examination, giant platelet clumping was seen (Figure 1). Platelet count was $60 \times 10^{9} / \mathrm{L}$ in a citrate tube. Favipiravir was stopped after 5 days, but pseudothrombocytopenia continued with a deep level of $5 \times 10^{9} / \mathrm{L}$ thrombocytes at the counter. He was discharged after 34 days with complications of concomitant bacterial pneumonia and decubitis ulcers. The platelet number was $50 \times 10^{9} / \mathrm{L}$ at the counter at that time.

Patient Consent for Publication: Written informed consent was obtained from the patient.

Author Contributions: Concept - F.C., D.G., S.A., İ.D.; Design - T.K., D.G., İ.D.; Supervision - I.D., T.K., S.A.; Resources - F.C., D.G., S.A.; Materials - D.G., T.G.; Data

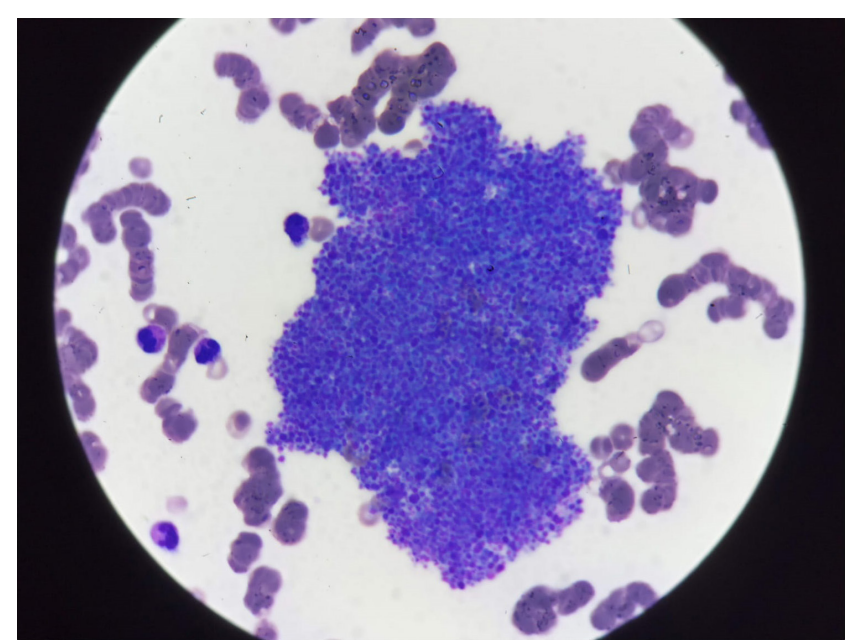

FIG. 1. Pseudothrombocytopenia with massive platelet clumping in a patient with COVID 19.

Collection and/or Processing - F.C., S.A., İ.D.;Analysis and/or Interpretation - F.C., D.G., T.G.; Literature Review - F.C., D.G.; Writing - F.C., D.G.; Critical Review - F.C., D.G., T.G., S.A., I.D.

Conflict of Interest: The authors have no conflicts of interest to declare.

Funding: The authors declared that this study has received no financial support.

\section{REFERENCES}

1. Saigo K, Sakota Y, Masuda Y. EDTA-dependent pseudothrombocytopenia: clinical aspects and laboratory tests. Rinsho Byori. 2005;53(7):646-653.

2. Fang CH, Chien YL, Yang LM, Lu WJ, Lin MF. EDTA-dependent pseudothrombocytopenia. Formos J Surg. 2015;48(3):107-109. [CrossRef]

3. Li H, Wang B, Ning L, Luo Y, Xiang S. Transient appearance of EDTA dependent pseudothrombocytopenia in a patient with 2019 novel coronavirus pneumonia. Platelets. 2020;31(6):825-826.[CrossRef].

4. Kuhlman P, Nasim J, Goodman M. Pan-pseudothrombocytopenia in COVID-19: a harbinger for lethal arterial thrombosis? Fed Pract. 2020;37(8):354-358. [CrossRef]

Address for Correspondence: Ferda Can, , Clinic of Hematology, Ministry of Health, Ankara City Hospital, Ankara, Turkey

e-mail: dr.ferda.can@hotmail.com

Received: December 2, 2020 Accepted: February 12, $2021 \cdot$ DOI: 10.5152/balkanmedj.2021.20229

Available at www.balkanmedicaljournal.org

ORCID iDs of the authors: F.C. 0000-0002-9899-1441; D.G. 0000-0003-3709-0372; T.G. 0000-0001-6313-0361; S.A. 0000-0003-4237-3342; I.D. 0000-0003-3217-9466.

Cite this article as:

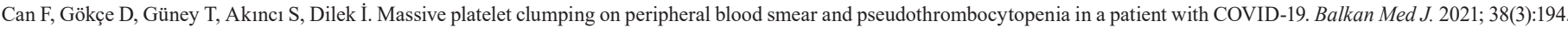

Copyright@Author(s) - Available online at http://balkanmedicaljournal.org/ 